\title{
Quão heterogêneo é o setor público no Brasil? Uma análise das diferenças salariais entre os poderes executivo, legislativo e judiciário
}

Masashi Nakamura, Leonardo; Verzola Vaz, Daniela

Quão heterogêneo é o setor público no Brasil? Uma análise das diferenças salariais entre os poderes executivo, legislativo e judiciário

Administração Pública e Gestão Social, vol. 12, núm. 4, 2020

Universidade Federal de Viçosa, Brasil

Disponible en: http://www.redalyc.org/articulo.oa?id=351564289001

Esta obra está bajo una Licencia Creative Commons Atribución-NoComercial-SinDerivar 3.0 Internacional. 


\section{Quão heterogêneo é o setor público no Brasil? Uma análise das diferenças salariais entre os poderes executivo, legislativo e judiciário}

How heterogeneous is the public sector in Brazil? An analysis of the wage differences between the executive, legislative and judicial branches

¿Cuán heterogéneo es el sector público en Brasil? Un análisis de las diferencias salariales entre los poderes ejecutivo, legislativo y judicial

Leonardo Masashi Nakamura

Universidade Federal de São Paulo, Brasil

Redalyc: http://www.redalyc.org/articulo.oa?

nakamuraleo21@gmail.com

Daniela Verzola Vaz

Universidade Federal de São Paulo, Brasil

daniela.vaz@unifesp.br

Recepción: 18 Febrero 2018

Aprobación: 26 Abril 2019

Publicación: 01 Octubre 2020

\section{ReSUMEN:}

Este trabajo estudia la diferencia salarial entre los servidores de los Poderes Ejecutivo, Legislativo y Judicial en Brasil en 2015 y analiza en que magnitud esa diferencia está asociada a los atributos individuales del trabajador, tales como la escolaridad y la edad, y cuanto se debe a factores como la existencia de reglas propias para la determinación salarial en cada caso. La ecuación de ingresos muestra que mismo controlando por factores observables subsiste una importante diferencia salarial entre los Poderes: el grupo mejor remunerado es el Judicial federal, mientras que el peor es el Ejecutivo Municipal - el primero recibe 65,2\% a más y el segundo $46 \%$ a menos que el Ejecutivo Federal. La descomposición de Blinder-Oaxaca muestra que $75 \%$ de la diferencia salarial bruta entre los Poderes Judicial y Ejecutivo es atribuible a características no observables, lo que sugiere la existencia de estructuras salariales muy distintas en cada caso.

Palabras Clave: Empleo público, desigualdad salarial, descomposición de Blinder-Oaxaca.

\section{Resumo:}

Este trabalho mensura a diferença salarial entre os servidores dos Poderes Executivo, Legislativo e Judiciário no Brasil em 2015 e investiga quanto dessa diferença está associada às características individuais do trabalhador, como escolaridade e idade, e quanto se deve a fatores como a existência de regras próprias para a determinação salarial em cada Poder de governo. Os resultados da equação de rendimentos mostram que, mesmo controlados atributos observáveis dos trabalhadores, subsistem diferenças salariais pronunciadas entre os Poderes: o segmento pior remunerado é o Executivo municipal e o mais bem remunerado, o Judiciário federal, com rendimentos $46 \%$ inferiores e $65,2 \%$ superiores aos do Executivo Federal, respectivamente. A decomposição de Blinder-Oaxaca mostra que $75 \%$ da diferença salarial bruta entre o Judiciário e o Executivo não pode ser explicada pelas características observáveis dos servidores, o que sugere a vigência de estruturas salariais muito distintas em cada caso.

Palavras-CHAVE: Emprego público, desigualdade salarial, decomposição de Blinder-Oaxaca.

\section{Abstract:}

This work measures the wage difference among civil servants of the executive, legislative and judicial branches in Brazil in 2015 and analyzes how much of the wage gap is associated with the individual characteristics of the employee, such as education and experience, and how much of it is due to factors such as predetermined rules for salary determination in each case. Results from the wage equation show that even controlling for observable factors of the labor force, there remains a considerable wage gap: The most well paid branch is the federal judicial, and the worst one the local executive - the first earns $65.2 \%$ more, and the last earns $46 \%$ less than the federal executive branch. The Blinder-Oaxaca decomposition shows that $75 \%$ of the overall wage differential between the judicial and the executive branches are attributable to unobserved predictors, which is an evidence of huge differences in the pay structures of these groups. 
KEYWORDS: Public employment, wage inequality, Blinder-Oaxaca decomposition.

\section{INTRODUÇÃO}

A distribuição de renda no Brasil apresenta-se de forma muito desigual, ainda que o índice de Gini, que mede sua concentração, tenha diminuído de $0,545 \mathrm{em} 2004$ para $0,490 \mathrm{em} 2014$. Um grau tão acentuado de desigualdade pode limitar a igualdade de oportunidades na sociedade e inibir o desenvolvimento econômico.

Entre os diversos componentes da renda, o rendimento do trabalho de empregados representa mais de $43 \%$ do valor total declarado pelas famílias. Hoffmann (2014) mostra que essa parcela do rendimento possui uma razão de concentração quase tão elevada quanto o índice de Gini, incluindo tanto salários inferiores ao mínimo como a remuneração de executivos de grandes empresas.

Recentemente, o tema da desigualdade na distribuição do rendimento do trabalho voltou à tona por meio de notícias a respeito de "supersalários" auferidos por servidores públicos, isto é, salários que ultrapassam o teto remuneratório previsto na Constituição Federal para todos os Poderes ${ }^{[\mathrm{i}]}$. Na literatura acadêmica, a elevada desigualdade no setor público foi verificada empiricamente por meio do cálculo do índice de Gini, que mostrou que os rendimentos no setor público são mais concentrados que entre os trabalhadores formais do setor privado (Souza \& Medeiros, 2013; Daré \& Hoffmann, 2013).

Do exposto, considerando o impacto da desigualdade para a sociedade, este trabalho tem como objetivo estudar as diferenças salariais encontradas entre os servidores dos Poderes Executivo, Legislativo e Judiciário no Brasil no ano de 2015. Por meio do emprego da metodologia de Blinder-Oaxaca, busca-se identificar quanto do diferencial remuneratório entre os três Poderes está associado às diferenças nos perfis da mão de obra - captados por características observáveis dos trabalhadores, como escolaridade e experiência profissional - e quanto está associado a fatores não observáveis, como a ação dos sindicatos ou a legislação específica de cada Poder, que ocasionam uma segmentação salarial no interior do próprio setor público.

Justifica-se o presente trabalho tendo em vista a existência de uma vasta literatura a respeito do diferencial de rendimento entre o setor público e o privado no Brasil, mas poucos estudos a respeito das causas da desigualdade remuneratória no interior do setor público, particularmente entre os três Poderes. Dessa forma, busca-se contribuir com a questão da desigualdade salarial, analisando-a nesse segmento específico do mercado de trabalho, procurando auxiliar a compreensão de suas particularidades.

O artigo está organizado em seis partes, incluindo esta introdução. Na próxima seção, realiza-se uma revisão dos trabalhos adotados como base teórica para a construção do modelo econométrico e para a análise dos resultados. Apresentam-se, ainda, a evolução do emprego público no Brasil no período recente e evidências empíricas acerca de sua heterogeneidade salarial. Na sequência, apresentam-se a base de dados e a metodologia utilizadas. Por fim, são discutidos os resultados obtidos por meio da análise de regressão e da decomposição de Blinder-Oaxaca. A última seção sintetiza os principais resultados alcançados e tece as considerações finais.

\section{REFERENCIAL TEÓRICO E EVIDÊNCIAS DA LITERATURA}

Uma das teorias mais difundidas a respeito da determinação de salários é a teoria do Capital Humano, desenvolvida por Schultz e Becker na década de 1960. De forma geral, o investimento em capital humano - com vistas à acumulação de conhecimento e habilidades específicas - eleva a produtividade do trabalho e, consequentemente, permite auferir maiores níveis de renda (Schultz, 1961). Todavia, Lima (1980) observa que o investimento em educação é superestimado e que há outros fatores, como o estado de saúde do trabalhador e sua motivação, que também modificam a renda individual. Assim, o capital humano possui outras dimensões que vão além da educação e da experiência profissional, de maneira que não é possível 
afirmar que ele é resultado apenas de investimento. Além disso, existem habilidades que são inatas de cada trabalhador, como, por exemplo, as relativas à capacidade de cada indivíduo para absorver conhecimento.

A teoria do Salário de Eficiência explica que os empregadores pagam um salário acima do nível de equilíbrio de mercado porque a produtividade do trabalhador estaria diretamente ligada à sua percepção salarial. Segundo Fernandes (2002), essa corrente teórica argumenta que o salário recebido pelo trabalhador inclui sua dedicação e esforço, de forma que as empresas não estariam dispostas a reduzir o salário, uma vez que o custo pela redução dos esforços dos trabalhadores seria maior que o valor poupado. Uma das justificativas apresentadas que relaciona o nível de salário e a produtividade é a de que o salário de eficiência pode evitar que os trabalhadores tentem burlar as normas de conduta. Uma alternativa para o empregador seria monitorar seus trabalhadores, todavia, ele incorreria em altos custos de monitoramento. Fernandes (2002) faz a ressalva de que contratos mais complexos podem eliminar a necessidade de monitoramento com o estabelecimento de uma multa ou perda de bônus para os trabalhadores que forem pegos burlando as normas de conduta.

Ainda de acordo com a teoria do Salário de Eficiência, salários maiores estimulam os trabalhadores a permanecerem mais tempo na empresa, diminuindo o custo associado ao treinamento de novos trabalhadores e, assim, a perda de capital humano específico. A seleção adversa também é outro fator que justifica o pagamento de salários acima do nível de equilíbrio de mercado, tendo em vista que os empregadores não conseguem identificar os trabalhadores mais produtivos sem custos, já que estes são heterogêneos. Dessa forma, considerando que o salário de reserva do trabalhador está relacionado com sua produtividade, as firmas que ofertam um salário maior atraem candidatos, em média, mais produtivos.

Cumpre ressaltar que a determinação dos salários no setor público envolve elementos que vão além das decisões típicas de contratação de trabalhadores em um ambiente de mercado. Por esse motivo, as teorias do Capital Humano e do Salário de Eficiência devem ser analisadas à luz das peculiaridades deste setor de emprego. Com respeito à teoria do Salário de Eficiência, cumpre salientar que diversas carreiras no setor público não encontram equivalência no setor privado e estão diretamente relacionadas às competências do governo em seus níveis federal, estadual e municipal, previstas na Constituição Federal. Assim, o oferecimento de salários acima do nível de equilíbrio de mercado, além de ter como finalidade atrair os trabalhadores mais qualificados e evitar que estes burlem as normas de conduta organizacional, visa garantir a provisão eficiente dos bens e serviços públicos. Nesse sentido, Matias-Pereira (2004) observa que houve, na década de 1990 e início dos anos 2000, uma revalorização das chamadas carreiras típicas de Estado, por meio da criação de postos de trabalho e da fixação de salários mais atraentes, com o intuito de atrair os trabalhadores mais bem preparados para o exercício dessas carreiras.

No que tange ao capital humano, uma distinção importante em relação ao setor privado é a existência de requisitos mínimos de idade e formação para o exercício das diversas atribuições. Adicionalmente, grande parte dos funcionários públicos goza da garantia de estabilidade no emprego, assegurada após o cumprimento do período probatório, o que favorece a acumulação de experiência profissional. Algumas legislações específicas, como a do estado de São Paulo, premiam o servidor com o adicional por tempo de serviço. Assim, os retornos salariais em resposta ao acúmulo de anos de serviço são particularmente pronunciados e não necessariamente refletem o aumento da produtividade do trabalhador.

De acordo com Gregory e Borland (1999), as práticas salariais observadas no setor público podem ser melhor compreendidas à luz dos objetivos dos formuladores de políticas. Quando o objetivo é a maximização do bem estar social, dois critérios são considerados: o da eficiência nos gastos públicos, que visa à minimização dos custos de produção, e o da equidade social, que busca a correção das imperfeições de mercado. No primeiro caso, os salários praticados no setor privado serviriam como parâmetro para o setor público, ao passo que no segundo caso, o setor público praticaria níveis salariais acima dos observados no setor privado -particularmente em se tratando dos trabalhadores de baixa qualificação -, a fim de melhorar suas condições de vida. Evidência empírica nacional que sustenta essa visão advém de Belluzzo, Anuatti e Pazello (2005). Ao mensurarem o diferencial salarial público-privado por meio de regressões quantílicas, esses autores observam 
que a vantagem do setor público é maior na cauda inferior da distribuição condicional de salários, declinando à medida que se consideram os quantis superiores dessa distribuição ${ }^{[i i]}$.

Por outro lado, segundo Gregory e Borland (1999), quando o objetivo dos formuladores é a realização de seus próprios interesses, a preocupação com a maximização dos votos - no caso dos políticos - ou da magnitude do orçamento - no caso dos burocratas - nortearia a política salarial. Os políticos seriam particularmente sensíveis ao voto dos servidores, estando, assim, mais propensos a atender suas demandas salariais.

As atribuições de cada poder de governo, em matéria de controle das finanças públicas, também influenciam a maneira como os salários são fixados no setor público. Conforme explica Conti (2013), ao Poder Executivo cabe elaborar as leis orçamentárias, que são submetidas ao Poder Legislativo, a quem cabe propor emendas e aprovar o texto final. A execução orçamentária é atribuição do Poder Executivo, ao passo que a fiscalização financeira e orçamentária é da alçada do Legislativo. Para que o Poder Judiciário não fique excluído desse processo e para que sua autonomia financeira e administrativa, assegurada pelo art. 99 da Constituição Federal, seja preservada, no momento de elaboração da proposta orçamentária anual o Judiciário deve indicar a parcela do orçamento que contempla seus gastos - respeitando os limites fixados na lei de diretrizes orçamentárias. Alguns autores, a exemplo de Conti (2013), chamam a atenção para o fato de que nem sempre as propostas orçamentárias apresentadas pelo Judiciário e demais instituições independentes são respeitadas, ao passo que outros criticam a prerrogativa de magistrados e parlamentares de fixarem seus próprios vencimentos, defendendo a necessidade de ampliação do controle externo sobre os gastos com salários.

Carvalho (2017) mostra que, no âmbito do Judiciário, a mobilização corporativa da magistratura em torno de seus interesses de classe remonta o processo constituinte de 1988:

A conjunção entre a falta de transparência sobre as remunerações e um histórico de privilégios funcionais, inclusive tributários, submetidos apenas ao frágil controle interno dos Tribunais constituía a imagem de uma magistratura politicamente forte que integrava um Judiciário institucionalmente fraco, ao menos no plano da divisão dos poderes. Ainda assim, a ampliação do espaço profissional se configurava numa espécie de trincheira das associações da magistratura na esfera da negociação na constituinte. (Carvalho, 2017, p. 54)

Garcia e Carvalho Neto (2002) analisaram três mandatos na Prefeitura de Belo Horizonte no período compreendido entre 1989 e 2000, observando que o corporativismo influencia na relação entre o setor público e os sindicatos à medida que os gestores conduzem as relações de trabalho de forma fragmentada, restrita a certos grupos. Ademais, a descontinuidade política e administrativa, peculiaridades da administração pública, contribuem para a manutenção da visão individualista ou de um grupo específico vis-à-vis o interesse da instituição.

\section{Evolução do emprego público no Brasil e evidências da heterogeneidade salarial}

Com relação à evolução recente do emprego público no país, a Tabela 1, a seguir, mostra uma tendência geral de crescimento no número de servidores dos três Poderes no período de 2002 a 2015, embora tenham ocorrido variações negativas pontuais, a depender do ano e do Poder de governo considerados. De maneira geral, a expansão verificada acompanhou o dinamismo que a economia brasileira vivenciou até 2013, não tendo havido mudança substancial na divisão dos servidores entre os três Poderes ${ }^{[i i i]}$. 
Tabela 1 - Evolução do emprego público por Poder de governo (valores absolutos†) - Brasil, 2002-2015

\begin{tabular}{l|l|l|l|l}
\hline \multirow{2}{*}{ Ano } & \multicolumn{3}{l|}{ Poder de governo } & \multirow{2}{*}{ Total } \\
\cline { 2 - 5 } & Executivo & Legislativo & Judiciário & \\
\hline 2002 & 5.862 .194 & 122.920 & 207.202 & 6.192 .316 \\
2003 & 6.121 .180 & 125.634 & 204.069 & 6.450 .883 \\
2004 & 6.269 .669 & 120.275 & 211.515 & 6.601 .459 \\
2005 & 6.606 .903 & 141.171 & 223.097 & 6.971 .171 \\
2006 & 6.933 .748 & 145.686 & 237.518 & 7.316 .952 \\
2007 & 7.217 .235 & 158.344 & 245.070 & 7.620 .649 \\
2008 & 7.406 .807 & 163.861 & 251.597 & 7.822 .265 \\
2009 & 7.751 .678 & 183.626 & 247.043 & 8.182 .347 \\
2010 & 7.920 .088 & 170.117 & 261.760 & 8.351 .965 \\
2011 & 8.021 .233 & 188.486 & 270.690 & 8.480 .409 \\
2012 & 7.630 .285 & 181.548 & 310.930 & 8.122 .763 \\
2013 & 8.043 .802 & 214.155 & 279.603 & 8.537 .560 \\
2014 & 8.164 .333 & 198.466 & 285.619 & 8.648 .418 \\
2015 & 7.892 .518 & 210.139 & 283.260 & 8.385 .917 \\
\hline
\end{tabular}

Fonte: Relação Anual de Informações Sociais (RAIS), 2002 a 2015. Elaboração própria com base na Tabela 31 de Mattos (2011).

† Esses valores não incluem a administração indireta, ou seja, autarquias, fundações, órgãos autônomos e empresas públicas e de economia mista. São incluídos, portanto, os trabalhadores na administração direta regidos pela Consolidação das Leis do Trabalho (CLT), os servidores regidos pelo Regime Jurídico Único (federal, estadual e municipal) e os militares.

No tocante às esferas de governo, Mattos (2011) mostra que houve grandes alterações na composição do emprego público, com diminuição da participação das áreas federal e estadual e aumento do peso dos municípios. Comparando os anos de 1995 e 2007, o autor destaca que a participação do emprego público federal passou de 18,3\% para 15,2\%. Já na esfera estadual ocorreu um decréscimo de 43,7\% para 34,1\%, com acréscimo na esfera municipal de $37,9 \%$ para $50,7 \%$.

Um dos fatores responsáveis pelo aumento do peso dos municípios foi a promulgação da Constituição Federal de 1988, que, por um lado, descentralizou diversas atividades, principalmente aquelas ligadas à função social do governo, que respondem pela maioria dos postos de trabalho no setor público. Por outro, criou novos municípios, impactando diretamente no aumento da participação da esfera municipal no emprego público total, tendo em vista que os novos municípios exigem um número mínimo de servidores para o início de seu funcionamento (Instituto de Pesquisa Econômica Aplicada [IPEA], 2009).

No que se refere aos regimes de contratação praticados, o setor público engloba não apenas funcionários públicos ditos "estatutários", isto é, regidos por Estatutos de Funcionários Públicos, como também trabalhadores contratados sob as normas da Consolidação das Leis do Trabalho (os "celetistas") e indivíduos sem vínculo permanente com o setor público (como consultores, estagiários, bolsistas, entre outros). Enquanto os primeiros gozam da garantia de estabilidade no emprego após completarem três anos de efetivo exercício em cargo obtido por concurso público, os celetistas não detêm a prerrogativa de estabilidade e seus direitos se comparam aos dos trabalhadores formais do setor privado.

Vaz (2011) mostra que entre 1992 e 2008 houve uma diminuição de 24,7\% na participação de celetistas e um aumento de 64,8\% na de estatutários. Mattos (2011) ressalta que o aumento da proporção de estatutários decorreu do processo de privatização, que eliminou diversos postos de trabalho celetistas, principalmente nos anos 1990, e de mudanças ocorridas após 2003 nas regras de contratação para o serviço público, que favoreceram o preenchimento de vagas por meio de concurso público nas três esferas e nos três Poderes de governo. Além das privatizações, a terceirização de cargos de suporte também contribuiu para a eliminação de postos de trabalho celetistas, resultando na subcontratação, por meio de licitações públicas, de empresas prestadoras de atividades e serviços auxiliares, como limpeza, vigilância, transporte, serviços técnicos de informática e processamento de dados, entre outras. A mudança mais substancial, no entanto, foi verificada entre os indivíduos que não possuem vínculo estável com o setor público, que tiveram um aumento de 121\% 
entre 1992 e 2008 (Vaz, 2011). A expansão dessa forma de contratação foi impulsionada como forma de se cumprir a Lei de Responsabilidade Fiscal (Lei Complementar n. 101, 2000), que estabelece um limite de gastos - conforme a receita corrente líquida - para os três Poderes, considerando cada nível de governo. Dessa forma, esse tipo de contratação permite uma maior flexibilidade, sem a necessidade de assumir compromissos no longo prazo (aposentadorias e pensões), permitindo uma redução de gastos, caso haja a superação do limite estabelecido em lei.

Os diferentes regimes de contratação praticados pelo setor público por si só podem acarretar diferentes níveis de remunerações de seus empregados. Por exemplo, os adicionais de qualificação e por tempo de serviço podem elevar significativamente a remuneração dos funcionários estatutários de maior escolaridade e de maior idade vis-à-vis os empregados celetistas.

De fato, Daré e Hoffmann (2013), utilizando dados da Pesquisa Nacional por Amostra de Domicílios (PNAD/IBGE) de 1995 a 2009, mostram que a remuneração dos estatutários é superior à recebida pelos celetistas. Uma das causas apontadas pelos autores é o Plano Nacional de Desestatização, que ocasionou uma redução de 20,9\% na remuneração média dos servidores celetistas estaduais, sendo estes os mais penalizados. Por outro lado, os funcionários públicos estatutários conseguiram reajustes acima da inflação, principalmente quando considerado o período de 2002 a 2009. Em âmbito federal, o aumento obtido foi de 22,9\%. Independentemente do vínculo empregatício, os autores verificam, ainda, que a esfera federal possui uma remuneração superior à praticada na esfera estadual e esta, à municipal.

Bender e Fernandes (2006), utilizando dados da PNAD de 1992 a 2004, mostram que a desigualdade salarial no interior do setor público federal foi superior à desigualdade no setor privado no período de $1992 \mathrm{a}$ 2001. No restante do período essa tendência se inverteu. Já em nível estadual, o grau de desigualdade salarial mostrou-se mais próximo em ambos os setores. Por fim, na esfera municipal a desigualdade foi maior no setor público até 1999, tornando-se superior no setor privado de 2002 a 2004.

Para além das diferenças remuneratórias observadas entre as áreas de governo ou ocasionadas pelos diferentes regimes de contratação praticados, observa-se grande heterogeneidade salarial entre as carreiras, inclusive no interior de um mesmo poder de governo. Dias (2010) argumenta que o nível salarial é influenciado pela importância dada pelo governante a um determinado órgão ou carreira. Por esse motivo, os membros da Polícia Federal, da Receita Federal e do Ministério Público seriam beneficiados com maiores salários quando comparados aos órgãos ligados à área social.

\section{BASE DE DADOS}

A base de dados utilizada neste trabalho é a Relação Anual de Informações Sociais (RAIS), publicada pelo Ministério do Trabalho no ano de 2015.

A RAIS é um registro administrativo, de periodicidade anual, instituído em dezembro de 1975 pelo Decreto n. 76.900, possuindo abrangência nacional. Apresenta informações sobre o mercado formal de trabalho, captando diversas características individuais importantes para a realização deste trabalho, como faixa etária, grau de instrução, ocupação, remuneração, tempo de serviço, entre outros. A desagregação dos dados permite comparar os Poderes Executivo, Legislativo e Judiciário nos âmbitos federal, estadual e municipal de governo.

É importante ressaltar que a unidade de observação na RAIS não é o trabalhador, e sim o vínculo empregatício. Desse modo, um indivíduo constará em duplicidade na RAIS caso trabalhe em dois locais distintos e apresente dois vínculos empregatícios. Assim, o número de vínculos é superior ao número de trabalhadores observado.

A amostra foi formada por todos os vínculos empregatícios, independentemente do tipo, ocupados por trabalhadores com dezesseis anos ou mais de idade, em estabelecimentos cuja natureza jurídica fosse o Poder Executivo, Legislativo ou Judiciário, nas três esferas de governo (federal, estadual e municipal). Excluíram-se 
os trabalhadores vinculados a autarquias, fundações, órgãos autônomos e empresas públicas e de economia mista. A razão para tal reside no fato de não ser possível identificar a qual poder de governo estão associados os vínculos empregatícios em órgãos da administração indireta. Como o objetivo deste trabalho é analisar as diferenças salariais entre os Poderes Legislativo, Executivo e Judiciário e a análise de regressão inclui variáveis binárias para identificá-los, somente foram objeto de estudo os vínculos da administração direta, para os quais é possível essa diferenciação, com base nos dados da RAIS.

Foram considerados apenas os vínculos ativos em 31 de dezembro de 2015 e que não foram desligados ao longo de 2015 - assim, foram excluídos os aposentados, falecidos e aqueles que rescindiram o contrato de trabalho. Também foram eliminados da amostra os vínculos para os quais não estavam disponíveis informações de rendimento ou de ocupação.

Dessa forma, após os tratamentos e exclusões efetuados, a amostra obtida foi de 8.637 .741 observações, sendo que 94,4\% delas pertenciam ao Poder Executivo, 2,4\% ao Legislativo e 3,2\% ao Judiciário.

Entre as limitações da RAIS está o fato de ela não captar os rendimentos recebidos na forma de benefícios indiretos (por exemplo, direito de uso de imóvel funcional, passagens aéreas, direito de uso de veículo oficial, aparelhos celulares cedidos pelo empregador, reembolso de despesas médicas, etc.). Nem sempre há clareza sobre o caráter desses benefícios indiretos, se podem ser caracterizados como despesas operacionais, ou se podem ser considerados rendimentos do trabalho assalariado, representando, pois, parte dos rendimentos de funcionários do governo. Adicionalmente, esses benefícios não são distribuídos uniformemente, podendo diferir a depender da esfera e do Poder de governo. Em todo o caso, em virtude da falta de informações sobre a distribuição desses benefícios na RAIS, a comparação entre os salários realizada neste trabalho levou em conta, estritamente, a remuneração declarada pelo empregador, captada por meio da variável remuneração mensal do trabalhador.

\section{METODOLOGIA}

A metodologia adotada nesta pesquisa é a decomposição de Blinder-Oaxaca, comumente empregada no estudo da discriminação por gênero e por raça no mercado de trabalho. Preliminarmente, será apresentada a equação minceriana, cuja importância reside em permitir mensurar os efeitos da educação e da experiência profissional sobre o rendimento do trabalhador, sendo base para a decomposição de Blinder-Oaxaca.

\section{Equação Minceriana}

A equação minceriana busca explicar o rendimento do trabalhador em função de sua escolaridade e experiência no mercado de trabalho. Sua forma funcional, conforme exposto por Lemieux (2006), é dada por:

$$
\ln Y=\ln Y_{0}+r S+\beta_{1} X+\beta_{2} X^{2}
$$

Onde $\mathrm{Y}$ representa o rendimento do trabalho, $\mathrm{Y}_{0}$ é o rendimento obtido por um trabalhador sem experiência prévia nem instrução, $S$ são os anos de escolaridade e $\mathrm{X}$ representa a experiência do trabalhador no mercado de trabalho.

Como se vê pela formulação acima, o arcabouço da teoria minceriana está diretamente relacionado com a teoria do Capital Humano. Contudo, embora a equação minceriana seja útil para se mensurar empiricamente o nível de remuneração considerando a escolaridade e a experiência do trabalhador, ela não capta atributos pessoais relativos, por exemplo, à inteligência e à ambição individual, que são difíceis de serem mensurados, mas que influenciam na produtividade e, consequentemente, no rendimento do indivíduo. Além disso, Patrinos (2016) aponta que a variável experiência também capta questões institucionais, por 
exemplo, quando as empresas pagam um salário superior ao trabalhador com o intuito de reduzir os custos de rotatividade de mão de obra e monitoramento. Assim, considerando a teoria do Salário de Eficiência, parte desse salário de incentivo acaba sendo englobado pelo coeficiente de experiência. Por fim, outra restrição do modelo é a suposição de que o retorno à experiência seja igualitário para todos os níveis de escolaridade.

$\mathrm{Na}$ equação minceriana adotada neste artigo considerou-se como variável dependente o logaritmo natural do rendimento por hora, em Reais $(\mathrm{R} \$)$. A razão de se considerar o rendimento horário em lugar do valor mensal foi controlar as diferenças salariais decorrentes de diferenças na jornada de trabalho contratada. Para tanto, foi utilizada a remuneração média mensal do trabalhador, dividida por quatro para obter-se a remuneração média semanal. Em seguida, dividiu-se o valor obtido pela quantidade de horas contratuais na semana, resultando no rendimento por hora. As variáveis explanatórias escolhidas, elencadas a seguir, buscam determinar em que medida as características pessoais e as especificidades do trabalho do indivíduo influenciam no rendimento auferido:

- A idade, medida em dezenas de anos para evitar que os coeficientes sejam muito pequenos;

- O quadrado da idade medida em dezenas de anos, uma vez que a influência da idade sobre o logaritmo do rendimento não necessariamente é linear e, a partir de certa idade, pode ocorrer queda da produtividade do trabalho;

- O tempo de emprego atual do vínculo, já que é comum haver reajustes salariais e gratificações relacionados ao tempo de serviço, o que afeta o nível de remuneração recebida;

- Uma variável binária para sexo, indicando 1 , se é do sexo feminino, e 0 , caso masculino;

- Sete variáveis binárias para distinguir o grau de escolaridade: Ensino fundamental incompleto ou analfabeto, ensino fundamental completo, ensino médio incompleto, ensino médio completo (tomado como base), ensino superior incompleto, ensino superior completo, mestrado e doutorado;

- Quatro variáveis binárias para identificar as cinco regióes brasileiras: Norte, Nordeste (tomada como base), Centro-Oeste, Sul e Sudeste;

- Sete variáveis binárias para identificar o Poder e a esfera de governo: Poder Executivo federal (tomado como base), Poder Executivo estadual, Poder Executivo municipal, Poder Legislativo federal, Poder Legislativo estadual, Poder Legislativo municipal, Poder Judiciário federal e Poder Judiciário estadual.

- Seis variáveis binárias para discriminar o grupo ocupacional do vínculo: (1) Membros superiores do poder público, dirigentes de organizações de interesse público e de empresas, gerentes; (2) membros das forças armadas, policiais e bombeiros militares; (3) profissionais das ciências e das artes; (4) técnicos de nível médio (tomados como base); (5) trabalhadores de serviços administrativos; (6) trabalhadores dos serviços, vendedores do comércio em lojas e mercados; e (7) outros.

Cumpre observar que os dados sobre ocupação disponibilizados na RAIS seguem a Classificação Brasileira de Ocupações ( $\mathrm{CBO}$ ), que é o documento do Ministério do Trabalho que reconhece, nomeia e codifica as funções desempenhadas no mercado de trabalho brasileiro. A partir do exercício de 2003, a RAIS passou a divulgar as informações sobre ocupação de acordo com a CBO versão 2002, podendo-se verificar a classificação dos vínculos empregatícios segundo grandes grupos ocupacionais, subgrupos ocupacionais principais, subgrupos ocupacionais ou famílias ocupacionais. Essas formas de agregação das profissões são representadas, respectivamente, pelo primeiro, dois primeiros, três primeiros e quatro primeiros dígitos do código atribuído pela $\mathrm{CBO}$. Neste trabalho, a distribuição dos vínculos empregatícios leva em consideração os grandes grupos ocupacionais. A razão de se adotar a $\mathrm{CBO}$ é o fato de ela estar consagrada na literatura e também para se conservar a comparabilidade com os resultados de outros trabalhos sobre o tema, que se valem da mesma classificação, como, por exemplo, Mattos (2011[ IV ]).

Por fim, é importante destacar que não foi incorporado ao modelo o atributo raça, pois, do total de 8.637.741 vínculos empregatícios pertencentes aos Poderes Executivo, Legislativo e Judiciário na RAIS 
2015, apenas 595.080 (6,89\%) detinham informações referentes à cor do indivíduo. Embora seja inegável a importância do referido atributo para a análise de regressão, até mesmo por sugerir um possível indício de discriminação no interior do setor público, a sua inclusão implicaria redução substancial no número de vínculos a serem considerados no modelo. Adicionalmente, como a maior parte dos vínculos para os quais a informação sobre cor está disponível pertence ao Poder Executivo municipal, restringir a base de dados a esses vínculos tornaria a análise pouco representativa do setor público como um todo ${ }^{[\mathrm{v}]}$.

\section{Decomposição de Blinder-Oaxaca}

Firpo (2017) explica que a decomposição de Blinder-Oaxaca subdivide a diferença no rendimento médio de dois grupos de trabalhadores - por exemplo, homens e mulheres, ou brancos e não brancos - em um "efeito de médias" e um "efeito de parâmetros". No contexto da medição da discriminação econômica, o primeiro efeito representaria o diferencial de rendimentos que se deve a diferenças nas características observáveis dos trabalhadores - admitindo que essas características captem corretamente os fatores produtivos que afetam o rendimento do trabalho. Já o segundo efeito decorreria do fato de se atribuir retornos econômicos diferentes a indivíduos com atributos produtivos observáveis idênticos. Assim, um efeito de parâmetros positivo poderia ser indicativo de discriminação no mercado de trabalho.

No contexto deste trabalho, os diferenciais associados ao efeito de parâmetros não resultariam da discriminação entre grupos, mas de regras diferenciadas de determinação salarial, a depender do Poder de governo considerado. Desse modo, poder-se-ia inferir que o retorno salarial em função da escolaridade e da experiência é diferente para cada um dos grupos.

A decomposição de Blinder-Oaxaca será realizada considerando os três Poderes, tomados dois a dois para fins de análise das diferenças salariais. Com base no modelo minceriano exposto na seção anterior, temos:

$$
\ln Y_{j}=\alpha+\sum_{i} \beta_{i} X_{i j}+\mu_{j e m}
$$

Onde $\ln Y_{j}$ é o logaritmo natural do salário/hora, $\alpha$ é o intercepto, $X_{i}$ são variáveis explanatórias, $\beta_{i}$ são os coeficientes de regressão e $\mu_{j}$ são erros aleatórios. $\mathrm{O}$ subscrito $j=1,2, \ldots, n$ denota as observações da amostra, ao passo que $i=1,2, \ldots, k$ discrimina os regressores do modelo.

Considerando os subgrupos A e B, temos:

$\ln Y_{A}=\alpha_{A}+\sum_{i} \beta_{i A} X_{i A}+\mu_{A}$

$\ln Y_{B}=\alpha_{B}+\sum_{i} \beta_{i B} X_{i B}+\mu_{B}$

Considerando as equações 3 e 4 nos pontos médios das variáveis e admitindo que o termo de erro tem média nula, obtém-se:

$$
\begin{aligned}
& \overline{\ln Y_{A}}=\alpha_{A}+\sum_{i} \beta_{i A} \bar{X}_{i A} \\
& \overline{\ln Y_{B}}=\alpha_{B}+\sum_{i} \beta_{i B} \bar{X}_{i B}
\end{aligned}
$$

Subtraindo a equação (6) da (5) e somando e subtraindo o termo $\sum_{i} \beta_{i A} \bar{X}_{i B}$, tem-se:

$\overline{\ln Y_{A}}-\overline{\ln Y_{B}}=\left(\alpha_{A}-\alpha_{B}\right)+\sum_{i} \beta_{i A}\left(\bar{X}_{i A}-\bar{X}_{i B}\right)+\sum_{i} \bar{X}_{i B}\left(\beta_{i A}-\beta_{i B}\right)$

Dessa forma, a parcela $\sum_{i} \beta_{i A}\left(\bar{X}_{i A}-\bar{X}_{i B}\right)$ representa o efeito de médias, que se deve a diferenças nas características observáveis dos indivíduos, como escolaridade e idade. Em contrapartida, a parcela $\left(\alpha_{A}-\alpha_{B}\right)+\sum_{i} \bar{X}_{i B}\left(\beta_{i A}-\beta_{i B}\right)$ quantifica o efeito de parâmetros, que decorre de diferenças na maneira como os atributos observáveis dos trabalhadores são valorados e remunerados nos grupos A e B, ou de fatores institucionais associados a cada segmento do setor público. 


\section{RESULTADOS E DISCUSSÃO}

Uma análise descritiva preliminar dos atributos observáveis dos servidores é conduzida nesta seção, a fim de se compararem as diferenças entre os Poderes Executivo, Legislativo e Judiciário no tocante às características produtivas e demográficas dos trabalhadores. Dessa forma, as Tabelas 2 a 6 trazem algumas informações dos vínculos, segundo poder e área de governo.

Tabela 2 - Média das variáveis jornada semanal de trabalho, idade, tempo no emprego, remuneração média anual e remuneração em dezembro para os três poderes, segundo esfera de governo - Brasil, 2015

\begin{tabular}{|c|c|c|c|c|c|c|}
\hline \multirow[b]{2}{*}{$\begin{array}{l}\text { Natureza } \\
\text { Juridica do } \\
\text { estabelecimento }\end{array}$} & \multirow[b]{2}{*}{$\begin{array}{l}\mathrm{N}^{\mathrm{O}} \mathrm{de} \\
\text { vinculos }\end{array}$} & \multirow[b]{2}{*}{$\begin{array}{l}\text { Jornada } \\
\text { semanal } \\
\text { média } \\
\text { (horas) }\end{array}$} & \multirow[b]{2}{*}{$\begin{array}{l}\text { Idade } \\
\text { média } \\
\text { (anos) }\end{array}$} & \multirow[b]{2}{*}{$\begin{array}{l}\text { Tempo } \\
\text { médio } \\
\text { no } \\
\text { emprego } \\
\text { (meses) }\end{array}$} & \multicolumn{2}{|c|}{ Remuneração } \\
\hline & & & & & \begin{tabular}{|l|} 
Média \\
anual \\
(salários \\
mínimos)
\end{tabular} & $\begin{array}{l}\text { Valor } \\
\text { nominal } \\
\text { médio em } \\
\text { dezembro } \\
\text { de } 2015 \\
(\mathrm{R} \$) \\
\end{array}$ \\
\hline $\begin{array}{l}\text { Poder } \\
\text { Executivo }\end{array}$ & 8.154 .478 & 36,69 & 41,66 & 148,30 & 5,54 & $4.552,00$ \\
\hline Federal & 512.143 & 39,66 & 38,62 & 170,20 & 8,43 & $7.080,00$ \\
\hline Estadual & 2.587 .598 & 34,58 & 43,80 & 154,70 & 5,22 & $4.185,00$ \\
\hline Municipal & 5.054 .737 & 35,83 & 42,57 & 120,00 & 2,96 & $2.392,00$ \\
\hline $\begin{array}{l}\text { Poder } \\
\text { Legislativo }\end{array}$ & 208.167 & 37,46 & 43,16 & 91,08 & 8,94 & $6.993,00$ \\
\hline Federal & 31.662 & 40,01 & 42,93 & 80,29 & 12,77 & $9.105,00$ \\
\hline & & & & 107,80 & 9,40 & $7.812,00$ \\
\hline Municipal & 107.474 & 36,81 & 42,03 & 85,15 & 4,64 & $4.063,00$ \\
\hline $\begin{array}{l}\text { Poder } \\
\text { Judiciário }\end{array}$ & 275.096 & 38,13 & 43,40 & 160,40 & 14,31 & $11.572,00$ \\
\hline Federal & 104.942 & 39,41 & 43,14 & 151,70 & 16,15 & $12.829,00$ \\
\hline Estadual & 170.154 & 36,84 & 43,66 & 169,10 & 12,47 & $10.316,00$ \\
\hline
\end{tabular}

Fonte: RAIS 2015. Elaboração própria.

Vê-se que a remuneração nominal com a data base de dezembro de 2015 é, em média, muito superior no Poder Judiciário: R \$1 1.572,00, contra cerca de R \$6.993,00 no Poder Legislativo e R \$4.552,00 no Executivo. Parte dessa diferença salarial reflete o fato de os trabalhadores do Judiciário serem, em média, mais velhos e terem uma jornada semanal de trabalho mais longa, conforme evidenciam os dados da Tabela 2. O maior tempo médio no emprego também justifica parte da diferença de remuneração em favor desse grupo. Por outro lado, o menor tempo no emprego dos servidores do Legislativo (91,1 meses) decorre dos ciclos eleitorais que ocorrem a cada quatro anos, propiciando a renovação de parte do quadro de funcionários desse poder de governo. Especificamente para o Senado, o mandato possui duração de oito anos, porém, com renovação de parte do quadro a cada quadriênio.

A Tabela 3 mostra a distribuição dos vínculos empregatícios segundo nível de escolaridade, para os três poderes, no ano de 2015. Verifica-se que os servidores do Judiciário são, em média, mais escolarizados, já que uma proporção maior deles detém diploma universitário. Do total de vínculos nesse segmento, 76,23\% completaram um curso superior, em contraposição a 42,28\% no Executivo e 34,81\% no Legislativo. 
Tabela 3 - Distribuição dos vínculos empregatícios dos três Poderes, segundo nível de escolaridade (\%) - Brasil, 2015

\begin{tabular}{|c|c|c|c|}
\hline \multirow{2}{*}{ Nivel de escolaridade } & \multicolumn{3}{|l|}{ Poder } \\
\hline & Executivo & Legislativo & Judiciário \\
\hline Analfabeto & 0,12 & 0,03 & 0,00 \\
\hline $\begin{array}{l}\text { Ensino fundamental } \\
\text { incompleto ou } \\
\text { completo }\end{array}$ & 15,30 & 11,33 & 1,19 \\
\hline $\begin{array}{l}\text { Ensino médio } \\
\text { incompleto ou } \\
\text { completo }\end{array}$ & 37,55 & 46,15 & 18,27 \\
\hline $\begin{array}{l}\text { Ensino superior } \\
\text { incompleto }\end{array}$ & 3,56 & 6,17 & 2,61 \\
\hline $\begin{array}{l}\text { Ensino superior } \\
\text { completo }\end{array}$ & 42,28 & 34,81 & 76,23 \\
\hline $\begin{array}{l}\text { Mestrado } \\
\text { Doutorado }\end{array}$ & $\begin{array}{l}1,05 \\
0,14\end{array}$ & $\begin{array}{l}1,39 \\
0,12\end{array}$ & $\begin{array}{l}1,53 \\
0,17\end{array}$ \\
\hline Total & 100,00 & 100,00 & 100,00 \\
\hline
\end{tabular}

Fonte: RAIS 2015. Elaboração própria.

A Tabela 4, a seguir, traz a distribuição dos vínculos segundo a Classificação Brasileira de Ocupações ( $\mathrm{CBO}$ ), considerada em seu nível mais agregado (grandes grupos ocupacionais). Considerando o total dos três Poderes, as ocupações mais relevantes são os profissionais das ciências e das artes (23,01\%), os técnicos de nível médio (20,73\%), os trabalhadores de serviços administrativos (17,33\%) e os trabalhadores dos serviços (16,01\%), que, em conjunto, perfazem quase $80 \%$ dos vínculos, em grande medida influenciadas pelo grande número de servidores no Executivo. Para esses grupos, os subgrupos ocupacionais de maior importância, no Poder Executivo, são os trabalhadores dos serviços, os escriturários, os professores leigos e de nível médio e os profissionais de ensino.

Já no Poder Legislativo, o grande grupo ocupacional de maior importância são os trabalhadores de serviços administrativos (52,23\%), com destaque para o subgrupo dos escriturários. No Judiciário destacamse os técnicos de nível médio (36,88\%), com bastante relevância do subgrupo ocupacional relacionado às atividades administrativas, e também os trabalhadores de serviços administrativos (28,48\%). Por fim, cumpre ressaltar que tanto no Legislativo como no Judiciário os membros superiores do poder público, dirigentes de organizações de interesse público e de empresas e gerentes respondem por mais de 1/4 dos vínculos. 
Tabela 4 - Distribuição dos vínculos empregatícios dos três poderes, segundo grande grupo ocupacional (\%) - Brasil, 2015

\begin{tabular}{|c|c|c|c|c|}
\hline \multirow{2}{*}{ Ocupação } & \multicolumn{3}{|l|}{ Poder } & \multirow{2}{*}{ Total } \\
\hline & Executivo & Legislativo & Judiciário & \\
\hline \multirow{4}{*}{$\begin{array}{l}\text { Membros das forças } \\
\text { armadas, policiais e } \\
\text { bombeiros militares } \\
\text { Membros superiores } \\
\text { do poder público, } \\
\text { dirigentes de } \\
\text { organizaçóes de } \\
\text { interesse público e de } \\
\text { empresas, gerentes }\end{array}$} & & & & \\
\hline & 8,33 & 0,10 & 0,11 & 7,87 \\
\hline & & & & \\
\hline & 8,86 & 26,13 & 27,61 & 9,87 \\
\hline $\begin{array}{l}\text { Profissionais das } \\
\text { ciências e das artes }\end{array}$ & 23,93 & 10,50 & 5,39 & 23,01 \\
\hline $\begin{array}{l}\text { Técnicos de nivel } \\
\text { médio }\end{array}$ & 20,60 & 4,83 & 36,88 & 20,73 \\
\hline $\begin{array}{l}\text { Trabalhadores de } \\
\text { serviços } \\
\text { administrativos }\end{array}$ & 16,06 & 52,23 & 28,48 & 17,33 \\
\hline Trabalhadores dos & & & & \\
\hline $\begin{array}{l}\text { Serviços, vendedores } \\
\text { do comércio em lojas } \\
\text { e mercados }\end{array}$ & 16,80 & 4,86 & 1,03 & 16,01 \\
\hline Outros & 5,44 & 0,01 & 0,51 & 5,18 \\
\hline Total & 100,00 & 100,00 & 100,00 & 100,00 \\
\hline
\end{tabular}

Fonte: RAIS 2015. Elaboração própria.

Nota: A categoria "Outros" inclui os trabalhadores agropecuários, florestais e da pesca, trabalhadores

da produção de bens e serviços industriais e trabalhadores em serviços de reparação e manutenção.

A Tabela 5 descreve a distribuição dos vínculos nos grandes grupos ocupacionais, segundo área de governo. $\mathrm{Na}$ esfera federal predominam os membros das forças armadas, policiais e bombeiros militares (41,05\%), com destaque para os primeiros, e os trabalhadores de serviços administrativos (19,95\%). Nas esferas estadual e municipal as ocupações mais relevantes são os profissionais das ciências e das artes $(21,57 \%$ e $25,16 \%$, respectivamente), representados majoritariamente pelos profissionais de ensino. Destacam-se, ainda, os técnicos de nível médio $(23,74 \%$ e $20,20 \%$, respectivamente) e os trabalhadores de serviços administrativos (17,53\% e 16,89\%, respectivamente). Em âmbito municipal, percebe-se, ainda, a relevância dos trabalhadores dos serviços $(22,11 \%)$. 
Tabela 5 - Distribuição dos vínculos empregatícios das três áreas de governo, segundo grande grupo ocupacional (\%) - Brasil, 2015

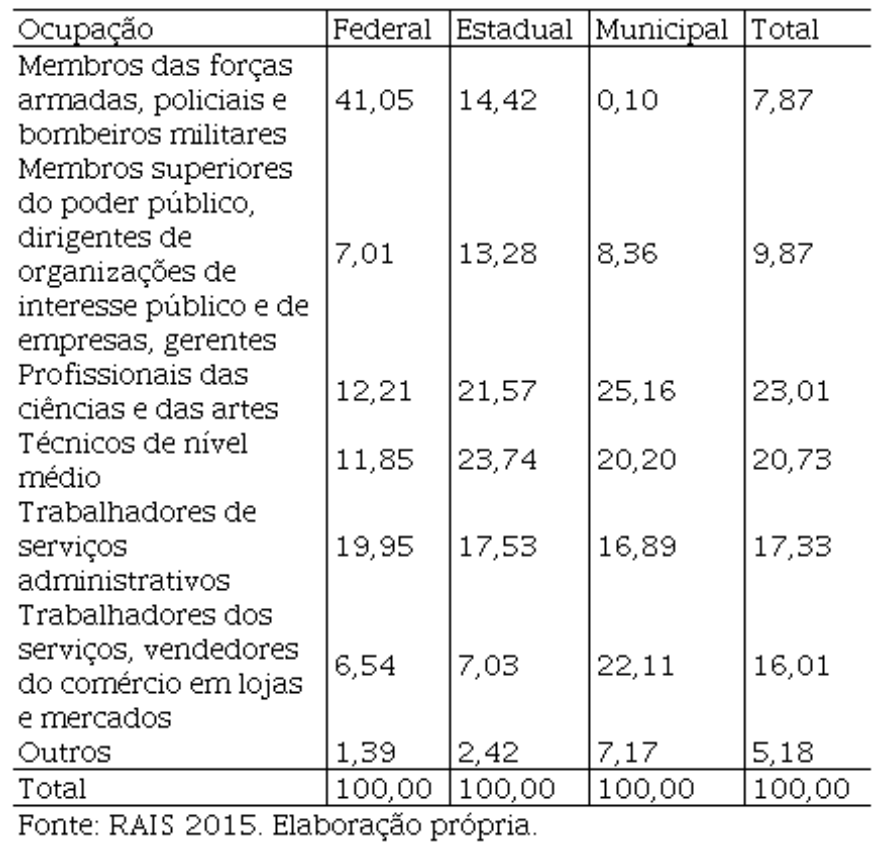

Fonte: RAIS 2015. Elaboração própria.

A análise descritiva realizada nesta seção permite inferir, portanto, que as diferenças de remuneração entre os três Poderes são, ao menos em parte, explicadas pelas diferenças nas características individuais observáveis dos servidores. Os trabalhadores do Judiciário são, em média, mais escolarizados, detêm maior tempo no emprego e se encontram em maior proporção em ocupações de maior complexidade, como aquelas reunidas no grande grupo ocupacional dos "Membros superiores do poder público, dirigentes de organizações de interesse público e de empresas, gerentes”. Na próxima seção, buscar-se-á observar o que ocorre com o diferencial salarial entre os poderes e áreas de governo quando esses fatores observáveis passam a ser controlados.

\section{Análise de Regressão}

Foram estimados dois modelos de regressão, sem e com variáveis explanatórias destinadas a captar o grande grupo ocupacional ao qual o vínculo empregatício pertence. Os resultados são apresentados na Tabela 6 e consideram erros-padrão robustos de White, a fim de corrigir a heterocedasticidade diagnosticada nos termos de erro. Todos os coeficientes estimados, em ambos os modelos, se revelaram estatisticamente significativos a um nível de significância de $1 \%$. O coeficiente de determinação $\left(\mathrm{R}^{2}\right)$ para a regressão sem controles para ocupação é de aproximadamente 46,5\%. Incluindo controles por grupo de ocupação, o poder explicativo do modelo eleva-se para 50,3\%. Esse percentual indica que aproximadamente metade da variabilidade nos logaritmos dos salários/hora é explicada pelo conjunto de regressores adotado. Uma limitação inerente ao modelo diz respeito ao fato de a RAIS captar informações a respeito da ocupação do indivíduo, mas não da função por ele exercida e sua classe e nível na carreira. Assim, obter-se-ia um modelo com maior poder explicativo caso fosse possível adotar, adicionalmente, controles para o nível hierárquico. 
Leonardo Masashi Nakamura, et al. Quão heterogêneo é o Setor público no Brasil? Uma análise das di...

Tabela 6 - Modelos de regressão estimados para o rendimento/ hora, com erros padrão robustos à heterocedasticidade - Brasil, 2015

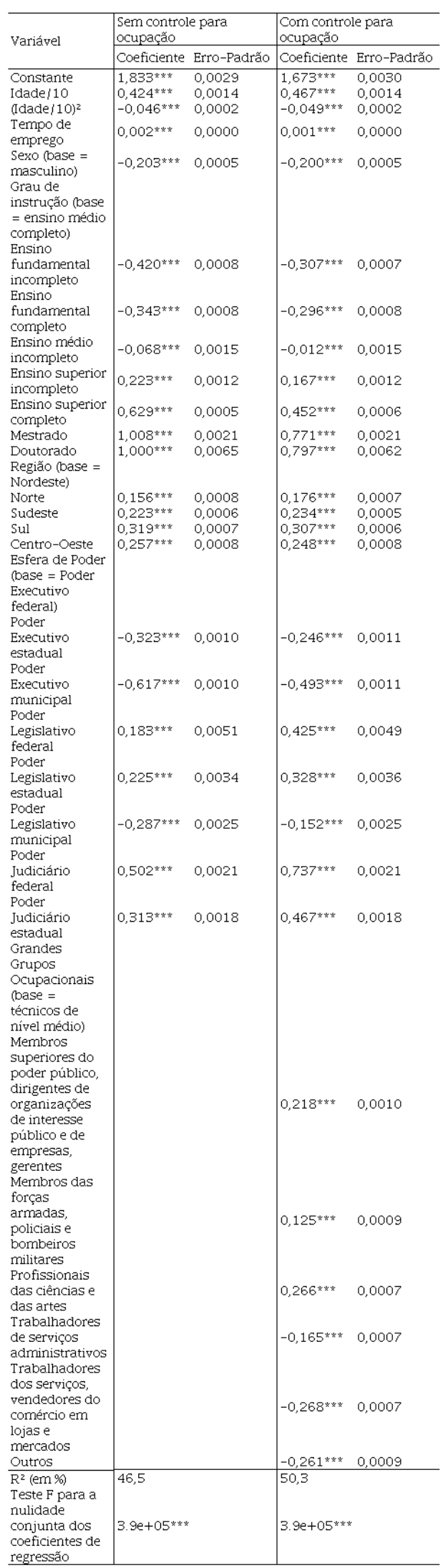


Fonte: RAIS 2015. Elaboração própria.

Notas: Número de observações: 8.637 .741 ; $^{* *}$ indica significância estatística ao nível de $1 \%$.

Os sinais dos coeficientes relacionados à idade convergem à teoria: o coeficiente associado à idade apresenta sinal positivo, denotando que o acúmulo de tempo no emprego afeta positivamente o nível da remuneração recebida pelo trabalhador. $\mathrm{O}$ coeficiente associado ao quadrado da idade, porém, possui sinal negativo, o que indica que apesar de os rendimentos crescerem com o tempo, há um ponto de inflexão nessa trajetória. Embora a teoria do Capital Humano associe esse resultado a aumentos de produtividade no trabalho derivados do acúmulo de experiência profissional, no caso do serviço público esse resultado é, em grande medida, uma decorrência natural do fato de muitas carreiras preverem adicionais e gratificações por tempo de serviço, independentemente do desempenho do trabalhador. A título de exemplo, o art. 129 da Constituição do Estado de São Paulo ${ }^{[v i]}$ assegura ao servidor público desta unidade da federação o recebimento de adicional por tempo de serviço, concedido por quinquênio, bem como a sexta-parte dos vencimentos integrais concedida aos vinte anos de efetivo exercício. O Estatuto do Servidor Público do Estado da Bahia ${ }^{[v i i]} \mathrm{em} \mathrm{seu}$ art. 77, inc. III, também prevê o adicional por tempo de serviço. A Lei Complementar n. 10.098/1994 ${ }^{\text {[viii] }}$ estabelece, em seu art. 100, inc. VIII, o adicional por tempo de serviço aos servidores públicos civis do Estado do Rio Grande do Sul ${ }^{[i x]}$.

Para aferir como o incremento marginal em uma variável explicativa afeta o rendimento por hora, admitidos os demais fatores constantes, o coeficiente estimado $\hat{\beta}$ associado a essa variável deve ser transformado conforme a expressão $[\exp (\hat{\beta})-1 \mid \cdot 100$.

O coeficiente associado à variável binária para sexo - cujo valor é - 0,203 , segundo a Tabela 6 - mostra que, em média e tudo o mais constante, o rendimento por hora da mulher é $[\exp (-0,203)-1] \cdot 100=18,4 \%$ inferior ao recebido pelo homem. A inclusão do controle para grupos ocupacionais não alterou esse resultado, que está em consonância com os achados da literatura. Vaz e Hoffmann (2007) analisaram os dados da PNAD no período de 1992 a 2005 , verificando que as mulheres recebem cerca de $28,3 \%$ menos que os homens no setor público. A diferença na magnitude do diferencial, em relação a este trabalho, deve-se às distintas bases de dados empregadas e ao recorte temporal e variáveis de controle considerados em cada caso.

O fato de subsistir uma diferença salarial por sexo, mesmo após o controle de diversos fatores que afetam o rendimento do trabalhador, sugere que possa ocorrer o "teto de vidro" no setor público, fenômeno caracterizado pela maior dificuldade com que alguns grupos demográficos, particularmente mulheres e negros, ascendem na carreira, o que leva à sua sub-representação nos cargos mais bem remunerados da hierarquia das organizações. Na administração pública federal os cargos de níveis mais altos, em geral, são providos por nomeação, o que significa que não necessariamente a seleção de pessoal obedece a critérios técnicos, como ocorre no momento de ingresso do servidor na carreira. Fontenele-Mourão(2006) mostra que a participação desigual da mulher nos cargos mais elevados da administração pública não é uma exclusividade do Brasil, uma vez que em países como Grã-Bretanha, Estados Unidos e Canadá ocorre o mesmo fenômeno. 
Os coeficientes associados às variáveis explanatórias para níveis de escolaridade mostram que trabalhadores com ensino fundamental incompleto $(\hat{\beta}=-0,420)$, ensino fundamental completo $(\hat{\beta}=-0,343)$ e ensino médio incompleto $(\hat{\beta}=-0,068)$ auferem rendimentos por hora, em média, $[\exp (-0,420)-1] \cdot 100=34,3 \%$, $[\exp (-0,343)-1] \cdot 100=29,0 \%$ e $[\exp (-0,068)-1] \cdot 100=6,6 \%$ inferiores aos percebidos por servidores com ensino médio completo. Por outro lado, o ensino superior completo ( $\hat{\beta}=0,629)$ eleva o rendimento em $[\exp (0,629)-1] \cdot 100=87,6 \%$. Nota-se que a inclusão dos controles ocupacionais ao modelo não modificou o sinal desses efeitos, mas reduziu suas magnitudes. Isso ocorre porque a classificação das ocupações segundo os grandes grupos da $\mathrm{CBO}$, ao levar em consideração a complexidade das atividades exercidas, indiretamente acaba por captar o nível de escolaridade do trabalhador. Assim, o controle por grupo ocupacional absorve parte do poder explicativo da escolaridade.

Merece destaque a ocorrência do efeito diploma no setor público, a exemplo do que se observa no mercado de trabalho em geral. Tal efeito é representado por um retorno salarial mais acentuado por um ano adicional de estudo quando este coincide com a conclusão de um ciclo escolar. Assim, observa-se que o retorno salarial para quem detém um diploma universitário $(87,6 \%)$ é bastante superior ao verificado para o indivíduo que cursa o ensino superior, porém ainda não o concluiu $([\exp (0,223)-1] \cdot 100=25,0 \%)$. Esse resultado é, em grande medida, esperado, visto que no setor público o efeito diploma é institucionalizado, pois a política salarial na maior parte das carreiras prevê adicionais por titulação. Por exemplo, a Lei n. 11.416/2006x, em seus art. 14 e 15, institui o adicional por qualificação aos servidores das Carreiras dos Quadros de Pessoal do Poder Judiciário Federal, atrelando-o à obtenção do título de Doutor, de Mestre, de certificado de Especialização ou de diploma de curso superior (desde que estes não constituam requisito para ingresso no cargo).

Os coeficientes associados às variáveis que discriminam os poderes e as áreas de governo mostram que, em média, os servidores do Poder Executivo estadual e municipal auferem um rendimento por hora $[\exp (-0,323)-1] \cdot 100=27,6 \% \mathrm{e}$ $[\exp (-0,617)-1] \cdot 100=46,0 \%$ inferior à categoria base (o Poder Executivo federal), respectivamente. Em relação ao Poder Legislativo, verifica-se que há diferenciais positivos nos âmbitos federal e estadual $([\exp (0,183)-1] \cdot 100=20,1 \%$ e $[\exp (0,225)-1] \cdot 100=25,2 \%$, respectivamente) e um diferencial negativo no âmbito municipal $([\exp (-0,287)-1] \cdot 100=-24,9 \%)$. No tocante ao Poder Judiciário, percebe-se que tanto os servidores pertencentes à esfera federal $([\exp (0,502)-1] \cdot 100=65,2 \%)$ como os da estadual $([\exp (0,313)-1] \cdot 100=36,8 \%)$ recebem uma remuneração muito superior aos servidores do Poder Executivo federal.

É interessante observar que a inclusão das variáveis ligadas à ocupação aprofundou, sobretudo em âmbito federal, o hiato salarial guardado pelos Poderes Legislativo ( $[\exp (0,425)-1] \cdot 100=53,0 \%)$ e Judiciário $([\exp (0,737)-1] \cdot 100=109,0 \%)$, relativamente ao Executivo. Então, há um indício de que as esferas de Poder citadas possuem um nível de remuneração mais elevado quando são comparados cargos com complexidades semelhantes.

Os dados apresentados permitem inferir que mesmo controlados os atributos que, segundo a teoria do Capital Humano, impactam na produtividade do trabalho e, assim, no rendimento, subsistem diferenças salariais pronunciadas entre os três poderes e as três esferas de governo. Por um lado, tais diferenças refletem o fato de o setor público brasileiro ser formado por um grande número de carreiras - somente no Executivo são 309 - que apresentam diferenças substanciais em suas estruturas, diferindo quanto ao número de classes e de níveis e também em relação ao interstício que o servidor deve cumprir para solicitar progressão e promoção. Essas diferenças traduzem a existência de práticas remuneratórias muito distintas entre os poderes de governo e as esferas subnacionais.

Por outro lado, a persistência do diferencial remuneratório também é resultado do maior poder de barganha de que algumas categorias dispóem ao reivindicar reajustes salariais. Carreiras mais fortalecidas ou pertencentes às áreas essenciais de atuação do Estado detêm maior capacidade de negociação ${ }^{[x i]}$. No Poder 
Judiciário, alguns grupos usufruem de maior poder de negociação, pois podem interferir no andamento de processos do Poder Executivo. Carvalho e Leitão (2013), ao analisarem o Supremo Tribunal Federal e o desenho institucional do Conselho Nacional de Justiça, concluem que a capacidade de barganha do Poder Judiciário decorre das prerrogativas funcionais relacionadas à inamovibilidade, irredutibilidade dos subsídios e vitaliciedade no cargo, aliadas à revisão judicial. $\mathrm{O}$ maior poder de barganha de alguns grupos do Judiciário pode muitas vezes conduzir à concepção equivocada de que esse poder de governo é mais importante que os demais, quando, na realidade, zelar pela aplicação das leis é tão importante quanto elaborá-las e quanto administrar o Estado e executar as políticas públicas.

\section{Análise da Decomposição de Blinder-Oaxaca}

As Tabelas 7 a 9 trazem os resultados da decomposição de Blinder-Oaxaca. A decomposição da diferença salarial bruta entre os Poderes Legislativo e Executivo (tomado como base), conforme a Tabela 7, mostra que as características observáveis do Poder Executivo são, em média, superiores às do Poder Legislativo, pois o efeito de médias é negativo, o que contribui para a redução da diferença salarial entre esses dois poderes. Desse modo, infere-se que, observando apenas o efeito de médias, os servidores do Executivo deveriam obter um rendimento/hora, em média, superior aos do Legislativo. Entretanto, o efeito de parâmetros não apenas é positivo, como também muito superior ao efeito de médias, o que se traduz em um hiato salarial em benefício do Poder Legislativo. Verifica-se, ainda, que as variáveis que mais contribuem para o efeito de médias são o tempo de emprego $(66,67 \%)$ e o grupo ocupacional (40,43\%), que traduzem o fato de os servidores do Executivo possuírem maior experiência no emprego e terem maior representatividade em ocupações de maior complexidade. No que tange ao efeito de parâmetros, merece destaque a alta contribuição da constante (112,97\%), indicando um "prêmio" a favor do Legislativo.

Tabela 7 - Decomposição da diferença no logaritmo do salário/ hora entre vínculos do Legislativo e do Executivo - Brasil, 2015

\begin{tabular}{l|l|l|l|l|l}
\hline Fator & $\begin{array}{l}\text { Efeito } \\
\text { de } \\
\text { médias } \\
\text { (A) }\end{array}$ & $\begin{array}{l}\text { Participação } \\
\text { (\%) }\end{array}$ & $\begin{array}{l}\text { Efeito de } \\
\text { parâmetros } \\
\text { (B) }\end{array}$ & $\begin{array}{l}\text { Participação } \\
(\mathbf{\%})\end{array}$ & $\begin{array}{l}\text { Diferença } \\
\text { total (A + } \\
\text { B) }\end{array}$ \\
\hline $\begin{array}{l}\text { Idade } \\
\text { Tempo de }\end{array}$ & $-0,011$ & 8,37 & $-0,377$ & $-79,54$ & $-0,388$ \\
emprego & $-0,090$ & 66,67 & 0,104 & 21,94 & 0,014 \\
Sexo & 0,028 & $-20,59$ & 0,034 & 7,22 & 0,062 \\
Escolaridade & $-0,016$ & 11,85 & 0,079 & 16,62 & 0,063 \\
Regiấ & 0,009 & $-6,74$ & 0,103 & 21,79 & 0,112 \\
Grupo & $-0,054$ & 40,43 & $-0,004$ & $-1,01$ & $-0,058$ \\
ocupacional & 0,000 & 0,00 & 0,536 & 112,97 & 0,536 \\
Constante & $0,00,134$ & $\mathbf{1 0 0 , 0 0}$ & $\mathbf{0 , 4 7 5}$ & $\mathbf{1 0 0 , 0 0}$ & $\mathbf{0 , 3 4 1}$ \\
\hline Total & $-\mathbf{0 , 1 3 4}$
\end{tabular}

Fonte: RAIS 2015. Elaboração própria.

Os resultados da decomposição da diferença salarial entre os Poderes Judiciário e Legislativo (tomado como base) são apresentados na Tabela 8. Verifica-se que tanto o efeito de médias como o de parâmetros contribuem para aumentar a diferença salarial em favor do Poder Judiciário, embora o efeito de médias seja superior ao de parâmetros. As variáveis que mais contribuem para o efeito de médias são a escolaridade $(52,20 \%)$ e o tempo de emprego $(39,01 \%)$, corroborando a análise descritiva, que mostrou que os servidores do Judiciário são, em média, mais escolarizados e detêm maior tempo de emprego se comparados aos outros poderes. Novamente, o resultado da decomposição mostra a participação relevante da constante para o 
efeito de parâmetros, o que reflete, em parte, as diferenças institucionais nas políticas salariais praticadas no Judiciário e no Legislativo.

Tabela 8 - Decomposição da diferença no logaritmo do salário/ hora entre vínculos do Judiciário e do Legislativo - Brasil, 2015

\begin{tabular}{|c|c|c|c|c|c|}
\hline Fator & \begin{tabular}{|l} 
Efeito \\
de \\
médias \\
(A)
\end{tabular} & $\begin{array}{l}\text { Participação } \\
\text { (\%) }\end{array}$ & $\begin{array}{l}\text { Efeito de } \\
\text { parâmetros } \\
\text { (B) }\end{array}$ & $\begin{array}{l}\text { Participação } \\
\text { (\%) }\end{array}$ & $\begin{array}{l}\text { Diferença } \\
\text { total (A+ } \\
\text { B) }\end{array}$ \\
\hline Idade & 0,012 & 2,31 & $-0,143$ & $-37,43$ & $-0,131$ \\
\hline $\begin{array}{l}\text { Tempo de } \\
\text { emprego }\end{array}$ & 0,204 & 39,01 & $-0,028$ & $-7,23$ & 0,176 \\
\hline $\begin{array}{l}\text { Sexo } \\
\text { Escolaridade } \\
\text { Região }\end{array}$ & $\begin{array}{l}-0,010 \\
0,273 \\
0,015\end{array}$ & $\begin{array}{l}-1,91 \\
52,20 \\
2,86\end{array}$ & $\begin{array}{l}0,016 \\
-0,110 \\
-0,258\end{array}$ & $\begin{array}{l}4,08 \\
-28,86 \\
-67,38\end{array}$ & $\begin{array}{l}0,006 \\
0,163 \\
-0,243\end{array}$ \\
\hline $\begin{array}{l}\text { Grupo } \\
\text { ocupacional }\end{array}$ & 0,029 & 5,54 & 0,078 & 20,09 & 0,107 \\
\hline Constante & 0,000 & 0,00 & 0,828 & 216,72 & 0,828 \\
\hline Total & 0,523 & 100,00 & 0,383 & 100,00 & 0,906 \\
\hline
\end{tabular}

Fonte: RAIS 2015. Elaboração própria. Importar tabla

A Tabela 9 detalha a decomposição da diferença salarial entre os Poderes Judiciário e Executivo (tomado como base), mostrando que tanto o efeito de médias como o de parâmetros atuam no sentido de aprofundar o hiato salarial em favor do Judiciário. No tocante às características observáveis, destaca-se novamente a importância da escolaridade (68,98\%) e do tempo de emprego (19,39\%), ambas superiores no Judiciário. Por outro lado, chama a atenção que a maior parte da explicação para a diferença salarial entre esses dois poderes de governo resida no efeito de parâmetros, principalmente pelo valor da constante, indicando que o Judiciário possui uma política salarial institucionalizada bem distinta do Executivo, auferindo um prêmio que, em sua maior parte, não pode ser explicado pelas características observáveis dos servidores.

Tabela 9 - Decomposição da diferença no logaritmo do salário/ hora entre vínculos do Judiciário e do Executivo - Brasil, 2015

\begin{tabular}{|c|c|c|c|c|c|}
\hline Fator & \begin{tabular}{|l} 
Efeito \\
de \\
médias \\
(A) \\
\end{tabular} & $\begin{array}{l}\text { Participação } \\
\text { (\%) }\end{array}$ & $\begin{array}{l}\text { Efeito de } \\
\text { parâmetros } \\
\text { (B) }\end{array}$ & $\begin{array}{l}\text { Participação } \\
(\%)\end{array}$ & $\begin{array}{l}\text { Diferença } \\
\text { total (A + } \\
\text { B) }\end{array}$ \\
\hline Idade & 0,012 & 3,94 & $-0,532$ & $-56,90$ & $-0,520$ \\
\hline Tempo de & 0,060 & 19,39 & 0,131 & 14,01 & 0,191 \\
\hline Sexo & 0,014 & 4,35 & 0,054 & 5,80 & 0,068 \\
\hline Escolaridade & 0214 & 68.98 & 0.012 & 1.24 & 0.226 \\
\hline Regiấo & 0,022 & 7,28 & $-0,152$ & $-16,26$ & $-0,130$ \\
\hline $\begin{array}{l}\text { Grupo } \\
\text { ocupacional }\end{array}$ & $-0,012$ & $-3,94$ & 0,059 & 6,25 & 0,047 \\
\hline Constante & 0,000 & 0,00 & 1,364 & 145,87 & 1,364 \\
\hline Total & 0,310 & 100,00 & 0,936 & 100,00 & 1,246 \\
\hline
\end{tabular}

Fonte: RAIS 2015. Elaboração própria.

A discrepância observada entre os três Poderes e até mesmo no interior de suas esferas estimula a busca dos servidores por isonomia salarial, que não necessariamente está embasada em aumentos de produtividade, $o$ que pode comprometer o equilíbrio das contas públicas. 
Godoi (2017) apresenta uma comparação internacional demonstrando que os valores iniciais pagos aos magistrados no Brasil (6.800 euros) superam os observados em países europeus como Alemanha, França e Espanha (cerca de 2500 a 3600 euros), o mesmo ocorrendo em cargos de nível médio no Judiciário.

A heterogeneidade dos sistemas de remuneração no interior do setor público também transparece quando o tema dos "supersalários" auferidos por servidores vem à tona, isto é, salários que ultrapassam o teto constitucional de $\mathrm{R} \$ 33.763,00^{[\mathrm{xii}]}$. Por meio do Gráfico 1 verifica-se que as maiores frequências relativas são observadas no Legislativo federal, com quase 3\% de "supersalários", e no Judiciário estadual, com 1,79\% deles. Esses resultados ajudam a compreender a magnitude do efeito de parâmetros quando comparados os rendimentos do Poder Legislativo com os do Executivo. Além disso, eles refletem o maior poder de barganha dos servidores dos Poderes Legislativo e Judiciário, relativamente aos do Executivo. Vale notar, por fim, que a menor incidência de valores acima do teto no Poder Executivo pode ser explicada pela existência de um redutor na folha de pagamentos desses servidores que automaticamente deduz da remuneração os valores que ultrapassam o teto constitucional.

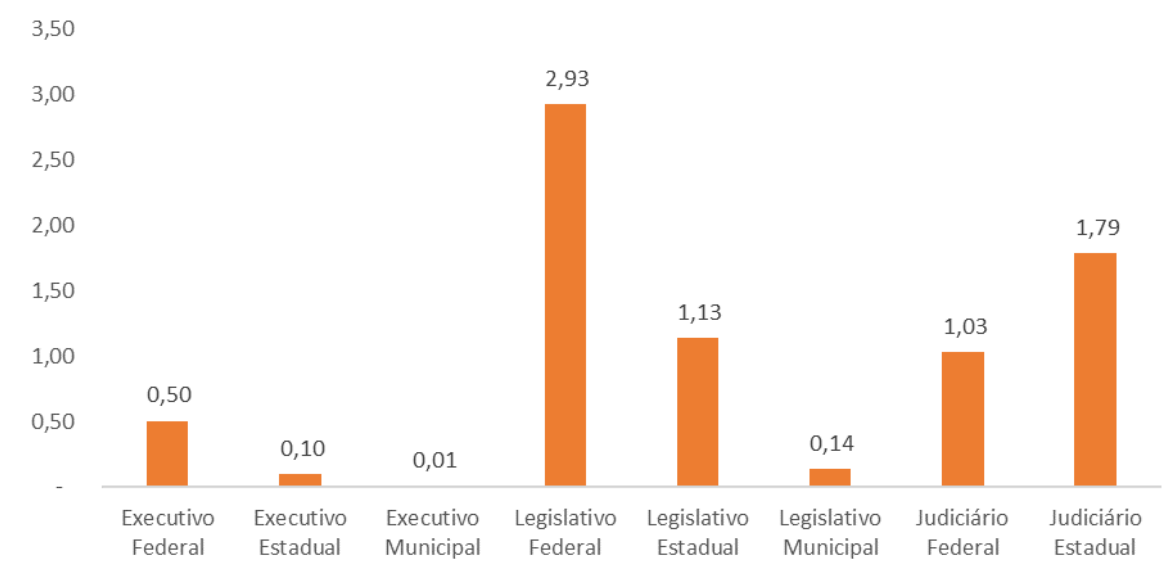

Gráfico 1 - Proporção de "supersalários" em relação ao número de vínculos de cada área e poder de governo (\%) - Brasil, 2015 Fonte: RAIS 2015. Elaboração própria.

Cardoso (2017) examina as práticas remuneratórias dos membros da carreira do Ministério Público do Estado de São Paulo, que se dividem em promotores e procuradores de justiça. A autora verifica que 96,9\% dos membros percebiam rendimentos mensais médios acima do teto constitucional em 2015. Apenas 3,1\% não superaram esse valor. A remuneração-base (composta pelo subsídio, sem contabilizar férias e $13^{\circ}$ salário) dos promotores de justiça ( $1^{a}$ entrância) era de $\mathrm{R} \$ 24.818,71$, e a dos procuradores de $\mathrm{R} \$ 30.471,11$, ambas, portanto, dentro do teto constitucional vigente à época. Porém, ao se somar a esses valores complementos remuneratórios (a título de vantagens, abonos, indenizações, outras indenizações e outros adicionais), a autora observa um incremento médio de $62,5 \%$ sobre a remuneração-base, de modo que o rendimento médio mensal dos membros dessa carreira jurídica em 2015 era de $\mathrm{R} \$ 46.036,30$.

Como medida para reduzir o gasto dos três Poderes, foi promulgada em 15 de dezembro de 2016 a Emenda Complementar n. 95, que estabeleceu um teto de gastos para as despesas da União. A referida Emenda discorre que as despesas totais só podem crescer de acordo com a inflação (aferida pelo Índice Nacional de Preços ao Consumidor Amplo [IPCA]) no período anterior. Está previsto, no entanto, um período de ajuste para o Legislativo e o Judiciário, durante o qual o Executivo compensará qualquer gasto superior ao teto efetuado por esses poderes ${ }^{[\mathrm{xii}]}$. Assim, existe uma margem para o aumento das despesas do Legislativo e do Judiciário acima do IPCA nos próximos anos, uma vez que a compensação por parte do Executivo somente cessará em 2020. Isso poderá elevar o hiato salarial a favor do Judiciário e do Legislativo, relativamente ao Executivo. 


\section{CONSIDERAÇÕES FINAIS}

O presente trabalho procurou investigar as causas da diferença salarial entre os três Poderes no Brasil no ano de 2015. A análise descritiva dos dados da RAIS mostrou que no Poder Judiciário aufere-se uma remuneração, em média, superior à dos outros dois poderes. Parte dessa diferença salarial é explicada pelas características observáveis dos servidores do Judiciário, que são, em média, mais velhos, mais escolarizados e detêm maior tempo de emprego. Por outro lado, a remuneração média percebida no Legislativo é maior que a do Executivo, embora o tempo de emprego e a escolaridade sejam mais elevados neste último.

A análise de regressão indicou que a vantagem salarial do Poder Judiciário se mantém mesmo quando passam a ser comparados indivíduos com atributos observáveis idênticos, isto é, mesmo sexo, idade, ocupação, escolaridade, região e tempo de emprego. Portanto, constata-se a existência de uma segmentação entre os poderes e esferas de governo, ocasionada por critérios distintos de determinação salarial.

Os resultados da decomposição de Blinder-Oaxaca corroboraram as análises descritiva e de regressão, mostrando que parte do hiato salarial a favor do Judiciário é explicada pelo efeito de médias, isto é, pelo fato de as características observáveis dos membros do Judiciário serem superiores, em comparação aos servidores dos outros dois Poderes. Todavia, há uma parte não explicada relevante, captada pelo efeito de parâmetros, que se deve a dois fatores: primeiro, ao fato de um mesmo atributo observável ser valorado e remunerado de modo distinto, a depender do poder de governo considerado; segundo, à diferença no valor da constante do modelo em cada caso. Já a comparação entre o Legislativo e o Executivo mostrou que o hiato salarial em favor do primeiro está relacionado apenas com a parte não explicada da decomposição de Blinder-Oaxaca. Desse modo, resulta argumentar que os servidores do Executivo deveriam auferir uma remuneração, em média, maior que os do Legislativo, caso fossem consideradas apenas as características observáveis dos trabalhadores no momento de definição dos salários.

Esses resultados sugerem, portanto, haver uma forte heterogeneidade nas práticas remuneratórias observadas no interior do setor público, com fatores distintos influenciando a formação dos salários em cada poder e esfera de governo. Embora sejam observados objetivos comuns de eficiência na provisão dos bens e serviços públicos, fatores políticos contribuem fortemente para a determinação salarial. Servidores que exercem funções estratégicas para o Estado têm maior poder de negociação no momento de definição da política salarial. Além disso, há categorias no Legislativo e no Judiciário que têm a prerrogativa de fixarem seus próprios vencimentos, estando sujeitas a um baixo grau de controle externo dos gastos efetuados com salários. Os grupos mais bem remunerados no serviço público exercem um efeito em cascata sobre os demais, que buscam equiparação de vencimentos, estando seu sucesso nesse processo condicionado ao seu poder de barganha, à sua capacidade de organização e representação e à sua proximidade com os núcleos decisórios.

Uma das limitações do trabalho está relacionada à metodologia empregada. Ao se adotar a regressão por mínimos quadrados, obtém-se a diferença salarial média entre os Poderes e esferas de governo, admitidos constantes os demais fatores do modelo. Embora a comparação entre médias seja importante para evidenciar o fato estilizado geral, ela pode encobrir diferenças nos extremos da distribuição de salários. Assim, trabalhos futuros poderão assumir um caráter menos generalista ao considerarem, em lugar da estimação por mínimos quadrados, regressões quantílicas, a fim de avaliar como se comporta o hiato salarial entre os Poderes de governo quando diferentes pontos da distribuição condicionada dos salários são considerados.

Análises desagregadas poderão, ainda, investigar de modo mais aprofundado as práticas remuneratórias observadas em carreiras específicas, a fim de se avaliar como a evolução temporal dos rendimentos se associa ao desempenho e ao treinamento dos servidores e se o plano de carreiras em vigor preserva amplitude salarial suficiente para estimular o desenvolvimento pessoal dos servidores. Análises complementares poderão, ainda, fornecer uma descrição detalhada da estrutura remuneratória em cada um dos três poderes, com comparação da participação das gratificações e das outras formas variáveis de remuneração no rendimento total. 


\section{REFERÊNCIAS}

Belluzzo, W., Anuatti, F., Neto, Pazello, E. T. (2005). Distribuição de salários e o diferencial público-privado no Brasil. Revista Brasileira de Economia, 59(4), 511-533.

Bender, S., Fernandes, R. (2006). Gastos públicos com pessoal: uma análise de emprego e salário no setor público brasileiro no período 1992-2004. Anais do Encontro Nacional de Economia, Salvador, BA, Brasil, XXXIV.

Cardoso, L. Z. L. (2017). Uma espiral elitista de afirmação corporativa: blindagens e criminalizaçôes a partir do imbricamento das disputas do Sistema de Justiça paulista com as disputas da politica convencional. (Tese de doutorado). Fundação Getúlio Vargas, São Paulo, SP, Brasil.

Carvalho, A. (2017). Juscorporativismo: os juízes e o judiciário na Assembleia Nacional Constituinte. Revista Brasileira de Estudos Politicos, 114(1), 31-77.

Carvalho, E., Leitão, N. (2013). O Poder dos Juízes: Supremo Tribunal Federal e o Desenho Institucional do Conselho Nacional de Justiça. Revista de Sociologia e Politica, 21(45), 13-27.

Constituição (1988). Constituição da República Federativa do Brasil. Recuperado de http://www.planalto.gov.br/cc ivil_03/Constituicao/Constituicao.htm.

Conti, J. M. (2013). Poderes não são independentes sem autonomia financeira. Revista Eletrônica Consultor Jurídico, $1(1), 129-132$.

Daré, E. F., Hoffmann, R. (2013). Remuneração do funcionalismo público e a variação da desigualdade da distribuição da renda no Brasil de 1995 a 2009. EconomiA, 14(1C), 645-670.

Dias, R. (2010). As carreiras no serviço público federal brasileiro: breve retrospecto e perspectivas. Texto para Discussão IPEA, 1482. Recuperado de http://www.ipea.gov.br/portal/images/stories/PDFs/TDs/td_1482.pdf

Emenda Complementar n. 95, de 15 de dezembro de 2016. (2016). Altera o Ato das Disposições Constitucionais Transitórias, para instituir o Novo Regime Fiscal, e dá outras providências. Diário Oficial da União. Brasília, DF, 16 dez. 2016. Seção 1, p. 2.

Fernandes, R. (2002). Desigualdade salarial: aspectos teóricos. In: C. H. Corseiul (Ed.), Estrutura salarial: aspectos conceituais e novos resultados para o Brasil (1-49). Rio de Janeiro: IPEA.

Firpo, S. (2017). Identifying and measuring economic discrimination. IZA World of Labor, 347. doi: 10.15185/ izawol.347

Fontenele-Mourão, T. M. (2006). Mulheres no topo de carreira. flexibilidade e persistência. Brasília: Secretaria Especial de Políticas para as Mulheres.

Garcia, G. S., Carvalho, A. C., Neto. (2002). Gestão das Relações de Trabalho no Serviço Público: Missão Impossível? Um estudo comparativo de três mandatos na Prefeitura de Belo Horizonte. Anais do Encontro Nacional da ANPAD, Salvador, BA, Brasil, XXVI.

Godoi, M. S. (2017). Finanças públicas brasileiras: diagnóstico e combate dos principais entraves à igualdade social e ao desenvolvimento econômico. Revista de Finanças Públicas, Tributação e Desenvolvimento, 5(5), 1-41.

Gregory, R. G., Borland, J. (1999). Recent Developments in Public Sector Labor Markets. In: Ashenfelter, O. e D. Card (Eds.), Handbook of Labor Economics, v. 3, cap. 53: 3573-3630. Elsevier/North-Holland.

Hoffmann, R. (2014). Transferências de renda e desigualdade, Brasil, 1995-2012: Análise de 11 parcelas da renda domiciliar per capita. Recuperado de https://www.researchgate.net/publication/312602109_TRANSFERENCIAS_DE_RENDA_E_DESIG UALDADE_BRASIL_1995-2012_Analise_de_11_parcelas_da_renda_domiciliar_per_capita

Instituto de Pesquisa Econômica Aplicada [IPEA]. (2009). Emprego público no Brasil: comparação internacional e evolução. Comunicado da Presidência, 19. Recuperado de http://www.ipea.gov.br/portal/images/stories/PDFs /comunicado/090330_comunicadoipea19.pdf.

Lemieux T. (2006). The "Mincer Equation" Thirty Years After Schooling, Experience, and Earnings. In: S. Grossbard (Ed.), Jacob Mincer A Pioneer of Modern Labor Economics (127-145). Boston, MA: Springer. 
Lima, R. (1980). Mercado de trabalho: o capital humano e a teoria da segmentação. Pesquisa e Planejamento Econômico, $10(1), 217-272$.

Matias-Pereira, J. (2004). Administração pública no Brasil: políticas de revalorização das carreiras típicas de Estado como fator de atração de novos talentos para o serviço público federal. Recuperado de http://repositorio.unb.b r/bitstream/10482/885/1/ARTIGO_AdministracaoPublicaBrasil.pdf

Mattos, F. A. M. (2011). Emprego público no Brasil: aspectos históricos, inserção no mercado de trabalho nacional e evolução recente. Texto para Discussão IPEA, 1582. Recuperado de http://www.ipea.gov.br/portal/images/sto ries/PDFs/TDs/td_1582.pdf

Patrinos, H. (2016). Estimating the return to schooling using the Mincer equation. IZA World of Labor, 278. doi: 10.15185 /izawol.278

Schultz, T. (1961). Investment in Human Capital. The American Economic Review, 51(1), 1-17.

Souza, P. H. G. F., \& Medeiros, M. (2013). Diferencial salarial público-privado e desigualdade de renda per capita no Brasil. Estudos Econômicos, 43(1), 5-28.

Vaz, D. V. (2011). Evolução da participação feminina no setor público brasileiro no período 1992-2008. In: M. A. Abreu (Org.), Redistribuição, reconhecimento e representação: diálogos sobre igualdade de gênero (p. 109-134). Brasília: IPEA.

Vaz, D. V., \& Hoffmann, R. (2007). Remuneração nos serviços nos anos 90: o contraste entre funcionários públicos e privados. Economia e Sociedade, 16(2), 199-232.

\section{Notas}

IEsse teto é estabelecido pelo art. 37 da Constituição Federal, em seu inciso XI - dado pela Emenda Constitucional n. 41/2003 -, e e impede que um servidor público possa ter remuneração que exceda o subsídio mensal, em espécie, dos Ministros do Supremo Tribunal Federal.

IINas esferas municipal e estadual, o comportamento decrescente do diferencial salarial ocasiona, inclusive, reversão do sinal do hiato, que se torna positivo para o setor privado em algumas situações.

IIIAinda que a RAIS seja uma base de dados confíavel para o estudo do setor organizado da economia, erros e omissóes podem ocorrer em virtude da forma de captação das informações, baseada na declaração do empregador. Isso poderia explicar algumas oscilaçôes pronunciadas observadas de um ano para outro na Tabela 1. Por esse motivo, privilegiou-se a análise da tendência geral mostrada pelos dados dessa tabela, em lugar da análise pormenorizada de variações interanuais.

IVVide Tabela 36, p. 94

VPara complementar o exposto, do total de 8.637 .741 vínculos, aproximadamente $58,52 \%$ (5.054.732 vínculos) estão alocados no Poder Executivo municipal. Todavia, quando considerado o universo de 595.080 vínculos $(6,89 \%)$ para os quais há informação sobre a cor do indivíduo, a proporção de vínculos associados ao referido Poder aumenta para 79,50\% (473.011 vínculos).

VIDisponível em https://www.al.sp.gov.br/repositorio/legislacao/constituicao/1989/compilacaoconstituicao-0-05.10.1989.html. Acesso em: 08 nov. 2018.

VIIDisponível em https://governo-ba.jusbrasil.com.br/legislacao/85381/estatuto-do-servidor-publico-do-estado-da-bahialei-6677-94. Acesso em: 08 nov. 2018.

VIIIDisponível em http://www.al.rs.gov.br/legiscomp/arquivo.asp?idNorma=527\&tipo=pdf. Acesso em: 08 nov. 2018.

IXÉ fato que em muitas carreiras não há gratificações por tempo de serviço, estando a obtenção de adicionais salariais atrelada à progressão por mérito, que depende de resultado favorável em avaliação de desempenho. Cumpre observar, no entanto, que a progressão muitas vezes é automática, sendo a avaliação de desempenho uma mera formalidade legal, realizada com a finalidade conceder promoções, em lugar de se analisar, de fato, a produtividade do trabalhador.

XDisponível em: http://www.planalto.gov.br/ccivil_03/_ato2004-2006/2006/lei/111416.htm\#anexoii. Acesso em: 08 nov. 2018. 
XIContribui, também, para a heterogeneidade dos reajustes salariais o fato de ainda não ter sido regulamentado no país o direito à negociação coletiva no serviço público.

XIIA variável utilizada para o cálculo do "supersalário" foi a média do valor da remuneração mensal nominal para o ano de 2015

XIIIO exposto encontra-se no art. $1^{\circ} \S 7^{\circ}$. O art. $1^{\circ} \S 8^{\circ}$ ressalva que a compensação não poderá exceder $0,25 \%$ do limite do Poder Executivo.

\section{BY-NC-ND}

